\title{
AUTOEVALUACIÓN Y EVALUACIÓN COMPARTIDA A TRAVÉS DEL USO DE RÚBRICAS. UNA EXPERIENCIA EN EDUCACIÓN PRIMARIA
}

\author{
Self and shared assessment using rubrics. An experience in primary school
}

Autoavaliação e avaliação partilhada através do uso de rubricas. Uma experiência na educação primária

Rodrigo Atienza Gago (1)

Alexandra Valencia-Peris (2)

(1) Universitat de València, España. Teléfono: +34 963983309. Correo electrónico: rodrigo.atienza@uv.es (2) Universitat de València, España. Teléfono: +34 963828920. Correo electrónico: alexandra.valencia@uv.es

\section{Resumen}

En este trabajo se describe y analiza una experiencia de evaluación alternativa llevada a cabo con instrumentos de autoevaluación. La propuesta se llevó a cabo en un grupo de $4^{\circ}$ de Primaria de 28 estudiantes, concretamente, en la asignatura Lengua Castellana y Literatura. Para evaluar al alumnado se empleó la ficha de autoevaluación del tema (al finalizar cada unidad didáctica) y la rúbrica de autoevaluación de actitudes en clase (al finalizar cada trimestre) a partir de criterios de evaluación consensuados con el alumnado. El proceso se ha acompañado de un diálogo permanente entre maestro y estudiantes en los casos de disparidad de opinión. Una vez analizada la experiencia, se concluye que se trata de una práctica que satisface tanto al docente como a los discentes y que es transferible a cualquier otra materia o etapa educativa una vez se adapten los criterios de evaluación utilizados.

Palabras clave: Autoevaluación; participación; rúbricas; educación primaria

\begin{abstract}
This work describes and analyzes an alternative evaluation experience based on selfassessment instruments. The proposal was carried out in the $4^{\text {th }}$ Grade of Primary School with 28 students, specifically, in the subject Spanish Language and Literature. In order to evaluate the students, the self-assessment form of the subject (at the end of each teaching unit) and the self-assessment rubric of attitudes in class (at the end of each trimester) were used based on evaluation criteria agreed upon with the students. The process has been
\end{abstract}


accompanied by a permanent dialogue between teacher and students in cases of disparity. Once the experience has been analyzed, it is concluded that it is a practice that satisfies both the teacher and the students and that is transferable to any other subject or educational stage once the evaluation criteria used are adapted.

Keywords: Self-assessment; participation; rubrics; primary school

\section{Resumo}

Neste trabalho descreve-se e analisa-se uma experiência de avaliação alternativa realizada com instrumentos de autoavaliação. A proposta foi realizada em um grupo com 28 alunos do 4. ${ }^{\circ}$ ano da escola primária, especificamente, na disciplinaLíngua Espanhola e Literatura. Para avaliar os alunos, utilizou-se uma ficha de autoavaliação da disciplina(no final de cada unidade didática) e a rubrica de autoavaliação de atitudes na aula (no final de cada trimestre) a partir de critérios de avaliação acordados com os alunos. O processo teve por base um diálogo permanente entre professor e alunos nos casos que houve disparidade de opinião. Uma vez analisada a experiência, conclui-se que é uma prática que satisfaz tanto o professor como os alunos e que é transferível para qualquer outra disciplina ou nível de ensino, desde que se adaptem os critérios de avaliação utilizados. Palavras-chave: Autoavaliação; participação; rubricas; educação primária

\section{Introducción}

Uno de los retos a los que se enfrenta el profesorado en España es pasar de modelos de aprendizaje bancario (centrados en la enseñanza del profesorado) a modelos alternativos (centrados en el aprendizaje del alumnado). Esto pasa por transformar los sistemas de evaluación, ya que estos determinarán las estrategias de aprendizaje del alumnado (López-Pastor, 2006). La experiencia que a continuación se presenta surge como un intento de transformar el proceso de evaluación en educación primaria. Para ello se han seguido dos estrategias: la participación del alumnado en su evaluación y la negociación curricular.

\section{Contextualización}

La experiencia se llevó a cabo durante el curso académico 2018/19 en un centro de educación primaria de la Comunidad Valenciana. En lo particular, la práctica se implantó 
en un grupo de $4^{\circ}$ de primaria de 28 estudiantes (11 alumnas y 17 alumnos), en la asignatura Lengua Castellana y Literatura (asignatura troncal común para todo el estado).

\section{Diseño y desarrollo}

La experiencia parte del interés docente por implicar al alumnado en el proceso de evaluación de su propio aprendizaje. En este caso concreto, el interés se centró en evaluar el cuaderno del alumnado y su actitud durante las sesiones de Lengua castellana y literatura. Se emplearon dos instrumentos diferentes: una ficha de autoevaluación del tema (anexo 1) utilizado al finalizar cada unidad didáctica; y una rúbrica de autoevaluación de actitudes (anexo 2), empleada al final de cada trimestre.

La ficha de autoevaluación del tema es una escala de valoración basada en los instrumentos presentados por Casado, Pérez-Pueyo \& Casado (2017). La elección y concreción de los distintos ítems fueron consensuados con el alumnado durante las primeras semanas del curso. Igualmente, la confección de la rúbrica de autoevaluación de actitudes fue resultado de la negociación entre el alumnado y su maestro. A partir de la autoevaluación el alumnado realiza una autocalificación no vinculante, e identifica las debilidades de su aprendizaje y cómo revertirlas (Anexo 1).

El desarrollo de la experiencia (Tabla 1) se realizó de la siguiente manera: una vez finalizada cada unidad didáctica el alumnado autoevaluaba su cuaderno y actitud durante las sesiones. Para ello empleaba la ficha de autoevaluación del tema y la anexaba a su cuaderno de clase. Por otro lado, al finalizar cada trimestre el alumnado rellenaba la rúbrica de autoevaluación actitudinal y la entregaba al maestro.

Tabla 1.

Desarrollo de la experiencia de autoevaluación.

\begin{tabular}{lll}
\hline Aspecto evaluado & \multicolumn{1}{c}{ Instrumento } & \multicolumn{1}{c}{ Momento } \\
\hline Cuaderno del alumnado & - Ficha de autoevaluación del tema & $\begin{array}{l}\text { - Al final de cada unidad } \\
\text { didáctica }\end{array}$ \\
& - Ficha de autoevaluación del tema & $\begin{array}{l}\text { - Al final de cada unidad } \\
\text { didáctica }\end{array}$ \\
Actitud en clase & $\begin{array}{l}\text { Rúbrica de autoevaluación } \\
\text { actitudinal }\end{array}$ & \\
\hline
\end{tabular}

Por su parte el docente revisaba los instrumentos de autoevaluación de cada estudiante y los contrastaba con las evidencias de aprendizaje del alumnado (que en este caso eran el propio cuaderno del alumnado y una ficha de seguimiento individual). Una vez revisados 
los instrumentos el docente podía citar a aquellas personas cuyos criterios distaban de los del docente para tratar de aclarar en dónde podía radicar la diferencia de criterios y, en ese caso, tratar de llegar a un consenso (Figura 1).

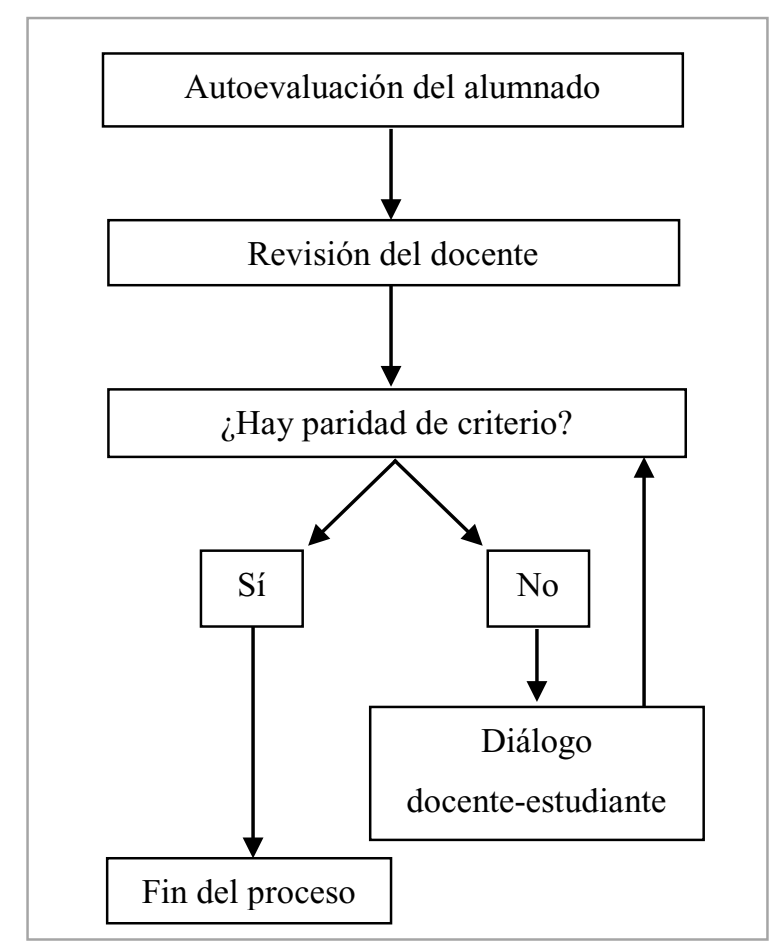

Figura 1.

Proceso de revisión docente de la autoevaluación del alumnado

\section{Evaluación}

La experiencia todavía está en proceso de desarrollo, por lo que su evaluación tiene un carácter parcial y provisional. A pesar de ello podemos extraer algunas ideas sobre cómo está resultando:

- El alumnado mayoritariamente se autoevalúa de forma honesta. Probablemente se deba a la gran insistencia por parte del docente en desligar la evaluación de la calificación. En esta misma línea, se ha empleado un tiempo suficiente en que el alumnado entienda la utilidad de realizar una correcta autoevaluación y su relevancia a la hora de detectar fallos y tratar de solucionarlos.

- El alumnado comprende qué está evaluando. A este respecto ha contribuido el hecho de colaborar en el proceso de evaluación, así como en el diseño de los instrumentos, seleccionando ítems de evaluación y definiendo y concretando los niveles de consecución de los instrumentos. 
- Ligado con los dos puntos anteriores, el alumnado es capaz de detectar los mayores aspectos a mejorar, si bien es cierto que el hecho de detectar el error no siempre va ligado a su corrección.

- Cuando ha habido disparidad de criterios entre el docente y el alumnado, las reuniones suelen ser útiles para llegar a un consenso. El hecho de que los instrumentos aborden aspectos concretos y las escalas definan convenientemente los grados de consecución contribuye a alcanzar acuerdos.

\section{Conclusiones}

Tanto docente como estudiantes manifiestan su satisfacción con los resultados obtenidos. Durante el proceso se ha hecho mucho hincapié en que el alumnado comprendiera el sentido de su participación en la evaluación y en ayudarle a detectar errores cometidos y cómo corregirlos, sin embargo, no se le ha acompañado tanto en el proceso de mejora. Este aspecto debe ser abordado en futuras ocasiones ya que es ahí donde puede producirse un aprendizaje más profundo y valioso.

Los ámbitos en los que se ha empleado la autoevaluación han sido básicamente procedimentales y actitudinales, por lo que consideramos una de las futuras líneas de actuación es incorporar al proceso de autoevaluación de aspectos conceptuales.

Esta experiencia es fácilmente transferible a otras asignaturas y etapas educativas siempre que se realicen las adaptaciones pertinentes a la madurez y conocimiento del alumnado y las características del grupo.

\section{Referencias}

Casado, O.M., Pérez-Pueyo, Á., \& Casado, P. (2017). La autorregulación en educación primaria. Una propuesta para favorecer la autonomía del alumnado. En V.M. López-Pastor \& Á. Pérez-Pueyo (Coords.), Buenas prácticas docentes. Evaluación formativa y compartida en educación: experiencias de éxito en todas las etapas educativas (pp. 208-237). León: Universidad de León.

López Pastor, V.M. (2006). La evaluación en educación física. Revisión de los modelos tradicionales y planteamiento de una alternativa: la evaluación formativa y compartida. Buenos Aires: Miño y Dávila. 


\section{Anexos}

Anexo 1. Ficha de autoevaluación del tema

\begin{tabular}{|c|c|c|c|c|c|}
\hline \multirow{3}{*}{ 密 } & \multicolumn{5}{|c|}{$\begin{array}{l}\text { Mi cuaderno está perfecto: está limpio y escribo con buena letra. Cada tema tiene su } \\
\text { portada, sus fichas de planificación y evaluación. Cada actividad tiene enunciado, } \\
\text { resultado, página y fecha): DOS cuadros }\end{array}$} \\
\hline & \multicolumn{5}{|c|}{$\begin{array}{l}\text { Mi cuaderno está bien presentado pero le falta alguna de los elementos fundamentales: } \\
\text { limpieza, buena letra, portada, fichas, enunciados, páginas o fecha: UN cuadro }\end{array}$} \\
\hline & \multicolumn{5}{|c|}{ Mi cuaderno está sucio, arrugado y mal presentado: NINGÚN cuadro } \\
\hline \multirow{3}{*}{ 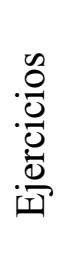 } & \multicolumn{5}{|c|}{ Respondo todos los ejercicios correctamente y los corrijo: DOS cuadros } \\
\hline & \multicolumn{5}{|c|}{ Suelo responder y corregir los ejercicios de forma correcta: UN cuadro } \\
\hline & \multicolumn{5}{|c|}{ Suelo hacer los ejercicios mal o de forma incompleta: NINGÚN cuadro } \\
\hline \multirow{2}{*}{$\frac{.4 \cdot \vec{\Xi}}{2}$} & \multicolumn{5}{|c|}{ Llevo la planificación al día: UN cuadro } \\
\hline & \multicolumn{5}{|c|}{ Llevo mucho retraso con la planificación: NINGÚN cuadro } \\
\hline \multirow{6}{*}{ 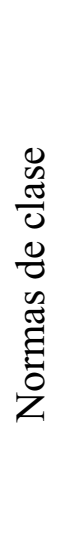 } & Norma & Mal (0) & Regular (1) & Bien (2) & Perfecto (3) \\
\hline & Tono de voz & & & & \\
\hline & Turno de palabra & & & & \\
\hline & Centrarse en la tarea & & & & \\
\hline & Hacer caso al maestro & & & & \\
\hline & Compañerismo & & & & \\
\hline
\end{tabular}

Ficha de autocalificación

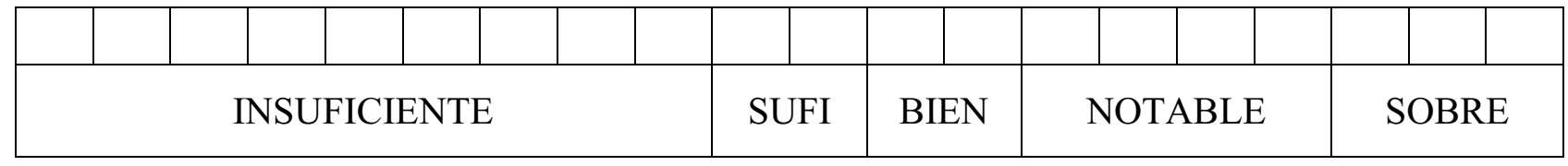

Para poder mejorar, el próximo tema debo... 
Anexo 2. Rúbrica de autoevaluación actitudinal

\begin{tabular}{|c|c|c|c|}
\hline \multicolumn{4}{|c|}{ Tono de voz } \\
\hline $\begin{array}{l}\text { Tengo dificultades } \\
\text { para modular el } \\
\text { tono de voz a pesar } \\
\text { de que me llamen la } \\
\text { atención. } \\
\text { Normalmente hablo } \\
\text { a un volumen más } \\
\text { elevado del nivel } \\
\text { establecido, lo que } \\
\text { provoca un mal } \\
\text { ambiente en clase. }\end{array}$ & $\begin{array}{l}\text { Muchas veces } \\
\text { hablo más alto del } \\
\text { nivel establecido. } \\
\text { Me tienen que } \\
\text { llamar la atención } \\
\text { casi todos los días } \\
\text { por hablar } \\
\text { demasiado alto. } \\
\text { Cuando me llaman } \\
\text { la atención corrijo } \\
\text { mi actitud. }\end{array}$ & $\begin{array}{l}\text { Normalmente hablo } \\
\text { en un tono de voz } \\
\text { adecuado, aunque } \\
\text { en determinadas } \\
\text { ocasiones (por } \\
\text { ejemplo, cuando } \\
\text { trabajamos } \\
\text { grupo, cuando me } \\
\text { enfado, etc.) elevo } \\
\text { el volumen por } \\
\text { encima del límite } \\
\text { establecido. } \\
\text { Cuando me llaman } \\
\text { la atención corrijo } \\
\text { mi actitud. }\end{array}$ & $\begin{array}{l}\text { Siempre hablo en } \\
\text { un tono de voz } \\
\text { adecuado. Nunca } \\
\text { me tienen que } \\
\text { llamar la atención } \\
\text { en este sentido. } \\
\text { Con mi actitud } \\
\text { favorezco un buen } \\
\text { ambiente en clase. }\end{array}$ \\
\hline
\end{tabular}

\begin{tabular}{|c|c|c|c|}
\hline \multicolumn{4}{|c|}{ Pedir y respetar el turno de palabra } \\
\hline $\begin{array}{l}\text { Todos los días me } \\
\text { tienen que llamar la } \\
\text { atención porque } \\
\text { hablo sin pedir el } \\
\text { turno de palabra. } \\
\text { Interrumpo } \\
\text { constantemente el } \\
\text { ritmo de clase. }\end{array}$ & $\begin{array}{l}\text { Muchos días me } \\
\text { llaman la atención } \\
\text { porque hablo sin } \\
\text { pedir el turno de } \\
\text { palabra. Interrumpo } \\
\text { al maestro o a mis } \\
\text { compañeras } \\
\text { compañeros. }\end{array}$ & $\begin{array}{l}\text { Normalmente pido } \\
\text { el turno de palabra } \\
\text { antes de hablar, } \\
\text { aunque a veces me } \\
\text { puede el } \\
\text { entusiasmo por } \\
\text { intervenir en clase. }\end{array}$ & $\begin{array}{l}\text { Siempre pido el } \\
\text { turno de palabra } \\
\text { antes de hablar. Si } \\
\text { tardan en darme el } \\
\text { turno de palabra } \\
\text { tengo paciencia y } \\
\text { espero. }\end{array}$ \\
\hline
\end{tabular}

\begin{tabular}{|c|c|c|c|}
\hline \multicolumn{4}{|c|}{ Centrarse en la tarea } \\
\hline $\begin{array}{lr}\text { Normalmente } & \text { me } \\
\text { distraigo en clase. } \\
\text { No aprovecho el } \\
\text { tiempo de clase. } \\
\text { Contribuyo } \\
\text { distraer a otras } \\
\text { compañeras } \\
\text { compañeros. }\end{array}$ & $\begin{array}{l}\text { Me distraigo con } \\
\text { mucha frecuencia. } \\
\text { Muchas veces me } \\
\text { tienen que llamar la } \\
\text { atención porque } \\
\text { juego con el } \\
\text { material escolar, } \\
\text { estoy dibujando o } \\
\text { hablando con otras } \\
\text { compañeras } \\
\text { compañeros. }\end{array}$ & $\begin{array}{l}\text { Normalmente estoy } \\
\text { centrada/centrado } \\
\text { en la tarea. A veces } \\
\text { me distraigo (por } \\
\text { ejemplo, hablando, } \\
\text { jugando } \\
\text { molestando a otras } \\
\text { compañeras } \\
\text { compañeros), pero } \\
\text { cuando me llaman } \\
\text { la atención } \\
\text { rectifico. }\end{array}$ & $\begin{array}{l}\text { Durante la clase } \\
\text { estoy } \\
\text { centrada/centrado } \\
\text { en la tarea: tengo el } \\
\text { material necesario } \\
\text { preparado, hago las } \\
\text { tareas durante el } \\
\text { tiempo de clase y } \\
\text { no me distraigo. }\end{array}$ \\
\hline
\end{tabular}




\begin{tabular}{|c|c|c|c|}
\hline \multicolumn{4}{|c|}{ Hacer caso al maestro } \\
\hline $\begin{array}{l}\text { Todos los días me } \\
\text { tienen que llamar la } \\
\text { atención porque no } \\
\text { atiendo las } \\
\text { indicaciones del } \\
\text { maestro. } \\
\text { Cuando me llaman } \\
\text { la atención no hago } \\
\text { caso. }\end{array}$ & $\begin{array}{l}\text { A menudo me } \\
\text { tienen que llamar la } \\
\text { atención porque no } \\
\text { hago caso al } \\
\text { maestro. En esos } \\
\text { casos soy capaz de } \\
\text { reconducir } \\
\text { actitud y atender, } \\
\text { aunque el efecto } \\
\text { dura poco. }\end{array}$ & \begin{tabular}{l}
\multicolumn{3}{l}{ Normalmente } \\
atiendo al maestro \\
cuando \\
hablando. \\
Hago caso cuando \\
pide alguna cosa, \\
aunque a veces \\
hablo con otras \\
personas, me \\
levanto de la silla, \\
me siento mal o no \\
presto atención \\
durante las \\
explicaciones.
\end{tabular} & $\begin{array}{l}\text { Siempre atiendo } \\
\text { cuando el maestro } \\
\text { está hablando. } \\
\text { Además, hago caso } \\
\text { cuando nos pide } \\
\text { algo (guardar } \\
\text { silencio, sentarnos } \\
\text { correctamente, } \\
\text { prestar atención a } \\
\text { las explicaciones, } \\
\text { etc.). }\end{array}$ \\
\hline
\end{tabular}

\begin{tabular}{|c|c|c|c|}
\hline \multicolumn{4}{|c|}{ Compañerismo } \\
\hline $\begin{array}{l}\text { Normalmente no } \\
\text { ayudo a nadie (o } \\
\text { casi nadie). } \\
\text { Mis compañeras y } \\
\text { compañeros de } \\
\text { grupo se quejan a } \\
\text { menudo de mi } \\
\text { comportamiento. } \\
\text { A veces mis actos } \\
\text { provocando } \\
\text { discusiones. } \\
\text { Alguna vez he } \\
\text { insultado, } \\
\text { molestado } \\
\text { agredido a otras } \\
\text { personas. }\end{array}$ & $\begin{array}{l}\text { Solo ayudo a las } \\
\text { persones con quien } \\
\text { tengo más amistad. } \\
\text { Muchas veces me } \\
\text { quejo del grupo del } \\
\text { que formo parte. } \\
\text { A veces molesto a } \\
\text { mis compañeras y } \\
\text { compañeros de } \\
\text { grupo. } \\
\text { En alguna ocasión } \\
\text { insulto a otras } \\
\text { persones. }\end{array}$ & $\begin{array}{lr}\text { Ayudo a las } \\
\text { compañeras } \\
\text { compañeros } \\
\text { quien con } \\
\text { amistad. } \\
\text { Normalmente no } \\
\text { pongo problemas } \\
\text { con las } \\
\text { agrupaciones. } \\
\text { Tengo un trato } \\
\text { respetuoso, aunque } \\
\text { a veces hablo o } \\
\text { actúo mal contra } \\
\text { una persona que me } \\
\text { cae mal. }\end{array}$ & $\begin{array}{l}\text { Siempre que puedo } \\
\text { ayudo a las } \\
\text { compañeras } \\
\text { compañeros, } \\
\text { incluso a las } \\
\text { persones con quien } \\
\text { no tengo mucha } \\
\text { amistad. } \\
\text { Nunca pongo } \\
\text { problemas con las } \\
\text { agrupaciones. } \\
\text { Acepto que siempre } \\
\text { tenemos que } \\
\text { tratarnos } \\
\text { respeto. con }\end{array}$ \\
\hline
\end{tabular}

